\title{
The Innovation Mechanism of the Low-carbon Economic Development in Hebei Province
}

\author{
Dongheng Hao, Dianru Wang, Ana Yin \\ Shijiazhuang Economic College, \\ Shijiazhuang, China
}

\begin{abstract}
This paper discusses the innovation mechanism of the development of the low-carbon economy in Hebei province. Put forward: The innovation mechanism of the technology, which relying on the major project of Hebei Province to achieve low-carbon core technology breakthrough and the establishment of low-carbon technology demonstration area and the application of low-carbon technology. The innovation mechanism of government performance evaluation system, which puts forward that an important step in developing low-carbon economy in Hebei province is to gradually changing GDP for the government performance appraisal system oriented which emphasis on carbon emissions and other pollutants emission index. The innovation mechanism of fiscal management, which put forward to increase financial input to support the lowcarbon industry and low-carbon technology development, accordingly to improve the low-carbon finance management system and improve the efficiency of fiscal funds support. The innovation mechanism of the carbon tax method, the leading role in carbon finance market should follow the market mechanism, strengthen the guiding role of government, construct the carbon trading platform, and gradually integrate into the unified national carbon trading market.
\end{abstract}

Keywords-Hebei Province; the low-carbon economy; innovation mechanism

\section{INTRODUCTION}

In 2007 September, President $\mathrm{Hu}$ Jintao clearly put forward the development of the low-carbon economy at the 15 APEC economic leaders meeting. In 2009 November, Premier Wen Jiabao chaired a State Council executive meeting, cleared up Chinese targets to 2020 of controlling greenhouse gas emissions and decided that the national carbon dioxide emissions in per unit of GDP in 2020 will drop 40-45\% than in 2005. The economic development of our country relies too heavily on the consumption of energy resources, which causes the amount of carbon emissions continue to increase. So, the low-carbon economy development in our country is particularly urgent. For this reason, the state puts forward the combination of developing low-carbon economy and the transformation of the mode of economic development, and actively promotion the pilot work of low-carbon cities. Industry in Hebei province is with features that the typical energy-consuming, high water consumption and low value-added. The iron and steel, textile, oil processing, chemical industry, medicine, building materials, and food seven industries which added value accounted for $80.5 \%$ of the industrial added value and contribution rate of industrial production growth accounted for $87.1 \%$. It is imperative for developing the low-carbon economy. This paper put forward the low-carbon economy innovation mechanism as the research starting point.

\section{THE INNOVATION MECHANISM OF THE TECHNOLOGY}

A. Relying on the Major Project to Achieve Low-carbon Core Technology Breakthrough

Hebei province should take advantage of the development of the low-carbon industry in the province, relying on the major projects in the fields of energy conservation and emissions reduction and low carbon, focus on science and technology resources, to research and development on the key generic technology which could achieve energy saving and emission reduction, finally to achieve low-carbon technology innovation. To give full play to Shijiazhuang city as the source function of the national semiconductor lighting industrialization base, relying on the implementation of "major semiconductor lighting product development and application demonstration" project, based on the design and manufacture of high-end chip with independent intellectual property rights as the core, and stronger to semiconductor lighting products production system that emphasis on epitaxial material production and the chip package as the focus, keep the dominant position in the country of the power type LED white light source and packaging technology. In the development of new energy and renewable energy industry, relying on the "Baoding Valley" construction as an opportunity, to carry out major projects, organize the research on photovoltaic technology, lithium battery storage technology and automatic control technology. By the state power Longyuan Shangyi Qilin mountain wind farm project and China Guyuan dam wind farm projects and the wind power project Zhangjiakou City, Chengde city and Cangzhou City and etc to improve the wind power equipment quality control and technical standard of wind power network [1].

\section{B. To Establish the Low-carbon Technology Demonstra-} tion Area and Apply Low-carbon Technology

Hebei Province should strengthen the existing integrated energy-saving and emission reduction technologies, through technical demonstration enterprise role in energy-saving and emission reduction fields, to put application and innovation of the low-carbon technology. In the field of building, through technical cooperation in 
the field of energy-saving building at home and abroad, to construct demonstration project to become the national building energy-saving demonstration base. Choose a mature area, put creating "national low carbon economy demonstration area" as the goal, to seize the opportunity of the inclusion of "national sustainable development experimentation area," create a national low carbon economy demonstration area actively and promote innovation and demonstration of low carbon technologies. Hebei province should promote constructing low carbon ecological demonstration city to develop low-carbon technologies innovation and energy-saving. Relying on the four ecological demonstration cities of the Tangshan Bay Metro in Tangshan City, Zhengding new area in Shijiazhuang city, New District of Beidaihe City in Qinhuangdao and Huanghua in Cangzhou City, in those area, to prefer testing the low-carbon ecological policies and technical standards of the state, and guide the construction of green traffic, green municipal, green building, renewable energy, and other special demonstration projects in these four demonstration area.

\section{THE INNOVATION MECHANISM OF GOVERNMENT PERFORMANCE EVALUATION SYSTEM}

Government performance evaluation, is the government itself or other social organizations through a variety of ways to do analysis, comparison, evaluation, and measurement the impact and effect in short-term and long-term of decision-making and management behavior of the government in the political, economic, cultural, environmental and etc. On the international experience, the main indexes of government performance evaluation including: economic indicators, efficiency, effectiveness, administrative ability, justice. If the government activities and investment as the measure, it might lead to government to waste of the resources, so, it must be based on the "results" as a measure of the performance of government [2]. According to our actual serious environmental problems, ecological environmental index should be as an important parameter in the government performance evaluation system. Those who ensure the coordinated development of economy and ecological environment should be rated as good or excellent grades; those who pursuit one-sided economic growth and results to the destruction of the ecological environment and make pollution index high cadres should be rated as "incompetent.” But influenced by traditional GDP leading performance, environmental pollution and other public policy implementation effect in control of environmental pollution tends to be weakened in the performance appraisal in the actual operation. In the constraints of the energy-saving and emission reduction targets, an important step in developing low carbon economy in Hebei province is to gradually changing GDP for the government performance appraisal system oriented which emphasis on carbon emissions and other pollutants emission index, guide the industrial enterprises to go low carbon economic development to change the path of the traditional "high carbon" economic dependence.

\section{THE INNOVATION MECHANISM OF FISCAL MANAGEMENT}

\section{A. To Increase Financial Input to Support the Low- carbon Industry and Low-carbon Technology Devel- opment}

In the project arrangements, Hebei province should increase $R \& D$ funds for energy-saving and emission reduction technology development and promotion. Pay attention to the input of the energy conservation and carbon reduction technology, increase the funding of energy-saving and emission reduction projects and support the integration of the financial fund, to establish special funds, finally get the formation of stable financial input mechanism. Second, increase the investment of new energy development and utilization. To strengthen the clean coal technology $R \& D$ system arrangement and innovation ability construction, realize the breakthrough in the field of clean coal technology; with the wind power key technology R\&D investment, using wind resources in Zhangjiakou area, we could actively cultivate and strengthen the wind power industry; continue to increase financial investment in R\&D of key technologies of solar photovoltaic power generation, improve the ability of independent research, relying on the Baoding photovoltaic industry, to improve the development and utilization of new energy. To increase financial investment on low carbon and low energy consumption of city construction, especially in the construction of city public traffic system, take the lead in the development of rail transportation in the provincial capital city; to establish special funds for green building for the promotion and application of green building incentives to reduce energy consumption and carbon emissions in the city [3].

\section{B. To Improve the Low-carbon Finance Management System and Improve the Efficiency of Fiscal Funds Support}

Hebei provincial budget arrangements for the development of low carbon economy should clear the capital application conditions, appropriate to use and other provisions, and should establish scientific and rational management measures. On the capital allocation method, the government can implement of "replace subsidies with awards," which will reward fund for the enterprises in energy conservation and emissions reduction with its actual work completed, and shorten delay rewards (allowance) to the enterprise.

\section{THE INNOVATION MECHANISM OF THE CARBON TAX METHOD}

A carbon tax is a pointer to the tax on $\mathrm{CO}_{2}$ emissions, it's a product tax on fossil fuels according to their carbon content in proportion to reduce fossil fuel consumption and $\mathrm{CO}_{2}$ emissions, which is expected to cut $\mathrm{CO}_{2}$ emissions to slow global warming. According to the Ministry of Finance Fiscal Science Research Institute (2009) study, taxation scope and object that China's present carbon tax may be defined as: in the production, 
operation and other activities process, directly emitted into the environment of $\mathrm{CO}_{2}$ due to consumption of fossil fuels. Because $\mathrm{CO}_{2}$ is generated from the consumption of fossil fuels, so the actual collection objects will eventually fall on coal, natural gas, oil and other fossil fuels. According to the taxation scope and object, the carbon tax can be identified as: units and individuals who directly emitted $\mathrm{CO}_{2}$ in the natural environment. On tax rate design, with $\mathrm{CO}_{2}$ emissions as the tax basis, and the ecological damage of $\mathrm{CO}_{2}$ emissions is directly related to its quantity, therefore, it can be taken from the amount of taxable mode, implement quota tax rate form of collection $[4,5]$.

From the developed countries in the practice of the construction of low carbon economy, the introduction of a carbon tax could reduce energy consumption and promote clean energy development. Therefore, in view of the situation of the industry structure in Hebei province, the province's carbon tax plan, in a planned, step-by-step to carry out a carbon tax policy is significant.

\section{A. Leading the Market Role in Carbon Finance and Strengthen the Guiding Role of Government}

Although the low carbon economy tide brings new opportunities for the development of the financial industry, but from Hebei or from a national perspective, carbon finance is far from enough in wide and deep. At present, one of the main differences in the carbon financing problem is who should be the dominated role, is the market or the government?

In the establishment of low carbon financing mechanism, we should emphasize the role of market mechanism. The market mechanism is a choice that must balance between efficiency and fair choice, transfer the supply and demand information of products and factors of production through the price signal, based on the mechanism of survival of the fittest, make more investment flows to valuable project and the enterprise. But in the promotion of low carbon finance, the government must play the guiding role, through the government funding and policy intervention can guide the private capital to enter the field of low carbon economic development, and gradually establish a market mechanism of low carbon finance [5].

In the aspect of promoting low carbon finance, according to the different degree of development of low carbon technology in Hebei Province, the new energy (such as solar power, wind power generation) development is still need to encourage private capital to enter in, to promote the commercial development and operation; For the key technologies and common technologies of energy-saving and emission reduction in industrial production, in the present situation, the government should set up public fund support and encourage attracting business investment to increase R\&D investment. For the renewable energy which does not have the market competitiveness but with commercial development prospects, the government should establish public funds to support.

\section{B. Constructing the Carbon Trading Platform and Gradually Integrated into the Unified National Car- bon Trading Market}

Carbon trading is a financial activity, to establish carbon trading market helps to increase the fund fluidity, can capable of efficient allocation of capital and other factors of production to enter the field of low carbon economic development. Hebei province should also actively carry out the practice of carbon trading platform, relying on Hebei institute of environment and energy exchange, to form a good docking and future national carbon trading market in order to facilitate the enterprises to make full use of carbon trading platform for low carbon fund. This trading platform in the initial stage is not necessarily true premises transactions. Through the provincial environmental supervision department, the labor department, development and Reform Commission and other departments of organization and coordination, to advance the establishment of carbon emissions database and network sharing platform to publish the relevant information using e-government network and carry out virtual market transactions. Under the supervision of a government department or the third party agency, let the enterprise or the institution who has intention of carbon emissions trading or low carbon investment sign the agreement, and gradually establish a solid carbon trading market.

\section{ACKNOWLEDGMENTS}

The research work was supported by Soft Science Key Project of Hebei Provincial under Grant No. 12457206D8, Grant No. 14457688D, and Grant No. 13454215D and Social Science Fundation of Hebei Provincial under Grant No. HB14GL029.

\section{REFERENCES}

[1] Hao Dongheng, Low Carbon Economy Development and Strategic Choice of Hebei Province. Peking University Press, 2013.

[2] Liu Junmin, The fiscal policy orientation of energy-saving and emission reduction in the period of "The Twelfth Five Year Plan" [J]. China Investment of Science and Technology, pp. 29-32, 2011.

[3] Wan Sha, Fiscal policy and the experience of the development of low carbon economy in developed countries, Green Finance, pp. 45-48, 2010

[4] Institute of Fiscal Science Research Group, The fiscal policy studies on promoting the development of low carbon economy in China, Finance and Trade Economics, pp. 11-16, 2011.

[5] Gong Jun, Chen Lei, The innovation of carbon finance business of commercial banks. Journal of Hunan College of Finance and Economics, pp. 73-78, 2011. 